\title{
O SUICÍDIO COMO QUESTÃO DE SAÚDE PÚBLICA
}

\section{Suicide as a public health issue}

\author{
Selena Mesquita de Oliveira Teixeira (OrclD) \\ Universidade de Fortaleza - UNIFOR - Fortaleza (CE) - Brasil \\ Luana Elayne Cunha Souza (OrcID) \\ Universidade de Fortaleza - UNIFOR - Fortaleza (CE) - Brasil \\ Luciana Maria Maia Viana (OrcID) \\ Universidade de Fortaleza - UNIFOR - Fortaleza (CE) - Brasil
}

Em uma perspectiva global, o suicídio apresenta-se, atualmente, como uma grave questão de saúde pública. Segundo registros da Organização Mundial da Saúde ${ }^{(1)}$, o suicídio vitimiza aproximadamente 800 mil pessoas por ano, o que significa uma morte a cada 35 segundos no mundo. O Brasil é o oitavo país em número absoluto de suicídios, registrando, em média, 11 mil casos por ano, isto é, 31 mortes por dia, sendo o número de homens quase quatro vezes maior que o de mulheres ${ }^{(2,3)}$.

Esses números podem ser ainda mais alarmantes quando se considera a subnotificação dos óbitos por suicídio. O número de casos de suicídio encontra-se camuflado entre registros de homicídios, acidentes e outras causas de morte. De qualquer forma, os registros oficiais disponíveis já permitem afirmar a gravidade desse fenômeno, que transcende a categoria de tragédia pessoal, configurando-se como um sério problema de saúde pública, especialmente em função da intensidade da dor, dos anos potenciais de vida perdidos e do seu caráter epidêmico ${ }^{(4,5)}$.

Mesmo diante desses dados e do reconhecimento da amplitude e da complexidade do fenômeno, o suicídio ainda é um tema tratado como tabu. De forma específica, é considerado como o ato humano de infligir a si próprio o fim da vida. Para sua delimitação, pode-se considerar como central a noção de intencionalidade de morte do indivíduo que tenta suicídio( ${ }^{(5)}$. Comportamentos suicidas não fatais se classificam, desde a ideação suicida - os diferentes níveis de pensamento que fomentam o suicídio, acompanhados de planejamento ou não - até a tentativa de suicídio, configurada como comportamento autolesivo em que há a intenção de pôr fim à vida(2).

A fronteira entre a ideação suicida, a tentativa de suicídio e o suicídio propriamente dito é muito tênue. Em geral, angústias e sofrimentos que sustentam a ideia ou intenção de suicídio podem atingir um nível avassalador e impulsionar o ato. Essa estreita fronteira alerta que a morte autoinflingida quase sempre é pensada, planejada e precedida por tentativas, ampliando, assim, as chances de intervenções preventivas imediatas e efetivas. Tal afirmação não descarta os casos que não passam por um planejamento, em geral, decorrentes de um impulso desesperador ${ }^{(6)}$.

Assim, o suicídio caracteriza-se como um fenômeno marcado pela complexidade, que se configura como processo humano e universal. Trata-se de um processo cuja causa não deve ser reduzida a um acontecimento específico. Desse modo, para compreendê-lo é primordial que seja considerada a trajetória de vida do indivíduo, sua subjetividade, bem como variáveis ligadas ao contexto histórico, econômico e cultural. Nessa perspectiva, o suicídio exige uma análise da culminação dos fatores psicossociais e das experiências singulares do indivíduo. A complexidade do suicídio reside na maneira como esses fatores se entrelaçam e, sobretudo, se potencializam ${ }^{(7)}$.

A dinâmica de diversos fatores de risco em um indivíduo vulnerável ocasiona o surgimento de uma dor psíquica que pode atingir intensidade intolerável, impedindo-o de enxergar outra possibilidade de sua interrupção que não seja antecipar o próprio fim. Esse conjunto de fatores é uma questão essencial quando se estuda o fenômeno do suicídio, podendo ser discutido no resgate de histórias de vida de pessoas que efetivaram suicídios ${ }^{(8)}$.

Conhecer os fatores que predispõem uma pessoa a tentar tirar sua própria vida é o primeiro passo para que se criem programas eficazes e efetivos de prevenção, bem como para a estruturação de políticas públicas, ou seja, 
um levantamento de alternativas sobre o que fazer com esse problema de saúde pública através de instrumentos e estabelecer um curso de ação( ${ }^{(9)}$.

$\mathrm{Na}$ análise dos fatores relacionados ao suicídio, a identificação de transtornos mentais é fundamental e pode ajudar o profissional da saúde a considerar clinicamente o risco e analisar as estratégias para reduzi-lo. Entre os transtornos mentais relacionados a casos de suicídio, tem-se transtornos do humor, sobretudo a depressão; transtornos mentais e de comportamento, resultantes do uso de substâncias psicoativas, como o alcoolismo; transtornos de personalidade, especialmente borderline, narcisista e antissocial; a esquizofrenia; e transtornos de ansiedade ${ }^{(10)}$.

Dentre os fatores de risco, destacam-se os de ordem psicológica, a exemplo de perdas recentes, má elaboração do luto de figuras parentais na infância, conflitos familiares, datas marcantes, reações de aniversário, personalidade impulsiva, agressividade marcante e humor lábil. Fatores sociodemográficos também podem ser influentes, como: sexo masculino; na faixa etária entre 15 e 35 anos e idosos acima de 75 anos; estratos econômicos extremos; residência em áreas urbanas; desemprego (principalmente perda recente do emprego); aposentadoria; isolamento social; ser solteiros ou separados. Algumas condições clínicas são consideradas pelo Ministério da Saúde como fatores de risco por serem, por vezes, incapacitantes, a exemplo de: doenças orgânicas intensas, dores crônicas, lesões desfigurantes, epilepsia, trauma medular, neoplasias malignas e presença do vírus $\operatorname{HIV}^{(4,5)}$.

Faz-se também necessário dedicar esforços à posvenção ao suicídio, a saber, o desenvolvimento de ações preventivas voltadas para amenizar os danos aos sobreviventes. A angústia daqueles que convivem com a lembrança de um suicídio deve ser vista com atenção pelos profissionais da saúde por representar um significante fator de risco para ocorrência de outros eventos da mesma natureza. Esse cuidado revela-se ainda mais necessário frente à ausência de redes e relações de apoio para a pessoa enlutada(11).

Ademais, o impacto de um suicídio pode se estender para, pelo menos, seis pessoas próximas ao falecido, que comumente passam a ter suas vidas profundamente afetadas, emocional, social e economicamente ${ }^{(12,13)}$. Destarte, entende-se que os esforços para promoção da saúde e a prevenção do comportamento suicida em todos os seus níveis de gravidade extrapolam os conhecimentos do campo da saúde. Tratando-se de fenômeno complexo e multideterminado, essas ações devem ser fundamentadas nos fatores de risco e proteção, bem como no conhecimento produzido por profissionais de diversas áreas do saber. Os conhecimentos gerados por esses profissionais podem contribuir para a redução dos índices de tentativa de suicídio e suicídio no Brasil e no mundo. Profissionais de saúde e assistência social, de todas as especialidades e níveis de atuação, devem estar qualificados para avaliar o risco de suicídio(1,3).

Sendo assim, a Revista Brasileira em Promoção da Saúde (RBPS) busca colaborar significativamente com o desafio de evidenciar um problema emergente e multidimensional, visto que apresenta atenção sobre este tema, almejando a ampliação dos conhecimentos sobre os fatores e a sensibilização dos profissionais da saúde, assim como dos profissionais de Direitos Humanos e das demais áreas implicadas. Nesse sentido, considera-se a verificação do risco de suicídio uma estratégia desafiadora no contexto da saúde pública, fator primordial para a prevenção, o manejo adequado da crise suicida e a promoção da saúde.

A colaboração da RBPS com a temática do suicídio ganha ainda mais relevância quando se constata uma lacuna nos estudos da suicidologia a respeito dos fatores e circunstâncias que promovem o desenvolvimento sadio e fortalecem recursos internos para o enfrentamento da crise suicida. Muito do que já se sabe envolve a questão do risco e suas implicações na vida da pessoa vulnerável. Para suprir essa lacuna, a RBPS almeja trazer à tona essas questões, que precisam ser discutidas por acadêmicos, profissionais e gestores de saúde, indicando como fundamental a ampliação do foco de investigação a partir de diferentes abordagens, perspectivas e campos do conhecimento. Conhecer os aspectos que possibilitam a superação da crise suicida pode constituir uma grande ferramenta para a construção de estratégias de prevenção mais precisas, às quais todos devem estar atentos.

\section{REFERÊNCIAS}

1. World Health Organization. Preventing suicide: a global imperative. Geneva: WHO; 2014.

2. Figueiredo AEB. Crise suicida: avaliação e manejo [resenhas]. Ciênc Saúde Colet. 2016;21(11):3633-4.

3. Ministério da Saúde (BR). Suicídio: saber, agir e prevenir. Bol Epidemiol. 2017;48(10):1-14.

4. D’Oliveira CF, Botega NJ. Prevenção do suicídio: manual dirigido a profissionais das equipes de saúde mental. Brasília: Ministério da Saúde; 2006. 
5. Bertolote JM, Mello-Santos C, Botega NJ. Detecção do risco de suicídio nos serviços de emergência psiquiátrica. Rev Bras Psiquiatr. 2010;32(Supl 2)S87-S95.

6. Minayo MCS, Cavalcante FG.Suicídio entre pessoas idosas: revisão da literatura. Rev Saúde Pública. 2010;44(4):750-7.

7. Figueiredo AEB, Silva RM, Vieira LJES, Mangas RMN, Sousa GS, Freitas JS, et al. É possível superar ideações e tentativas de suicídio? Um estudo sobre idosos. Ciênc Saúde Colet. 2015;20(6):1711-9.

8. Sérvio SMT, Cavalcante ACS. Retratos de autópsias psicossociais sobre suicídio de idosos em Teresina. Psicol Ciênc Prof. 2013;33(Nesp):164-75.

9. Hawlet M, Ramesh M, Perl A. Política Pública: seus ciclos e subsistemas. São Paulo: Campus; 2009.

10. Associação Brasileira de Psiquiatria. Suicídio: informando para prevenir. Brasília: Conselho Federal de Medicina; 2014.

11. Fukumitsu KO. Suicídio e luto: histórias de filhos sobreviventes. São Paulo: Digit Publ e Print; 2013.

12. Barenchtein N Netto, Werlang M, Rigo S. Suicídio: uma questão de saúde pública e um desafio para a psicologia clínica. Brasília: Conselho Federal de Psicologia; 2013.

13. Fukumitsu KO, Kovács MJ. Especificidades sobre processo de luto frente ao suicídio. Psico (Porto Alegre) 2016;47(1):3-12.

\section{Endereço para correspondência:}

Selena Mesquita de Oliveira Teixeira

Universidade de Fortaleza - UNIFOR

Programa e Pós Graduação em Psicologia

Av. Washington Soares, 1321

Bairro: Edson Queiroz

CEP: 60811-905 - Fortaleza - CE - Brasil

E-mail: selenateixeira@hotmail.com 